\title{
Response of the fine root production, phenology, and turnover rate of six shrub species from a subtropical forest to a soil moisture gradient and shading
}

\author{
Xiaoli Fu • Junlong Wang • Huimin Wang • \\ Xiaoqin Dai $\cdot$ Fengting Yang $\cdot$ Mei Zhao
}

Received: 28 June 2015 / Accepted: 21 September 2015 / Published online: 29 September 2015

(C) Springer International Publishing Switzerland 2015

\begin{abstract}
Background and aims Knowledge of the fine root dynamics of different life forms in forest ecosystems is critical to understanding how the overall belowground carbon cycling is affected by climate change. However, our current knowledge regarding how endogenous or exogenous factors regulate the root dynamics of understory vegetation is limited. The aims of this study were to test the effects of soil moisture gradient and shading on the fine root production, phenology, and turnover rate of six shrub species from a subtropical forest.

Methods We selected a suite of study sites representing different habitats with gradients of soil moisture and solar radiation (shading or no shading). We assessed the fine root production phenology, the total fine root production, and the turnover among six understory shrub species in a subtropical climate, and examined the responses of the fine
\end{abstract}

Responsible Editor: Alexia Stokes.

Electronic supplementary material The online version of this article (doi:10.1007/s11104-015-2686-z) contains supplementary material, which is available to authorized users.

X. Fu $\cdot$ J. Wang $\cdot$ H. Wang $(\bowtie) \cdot$ X. Dai $\cdot$ F. Yang Qianyanzhou Ecological Station, Key Laboratory of Ecosystem Network Observation and Modeling, Institute of Geographic Sciences and Natural Resources Research, Chinese Academy of Sciences, A11, Datun Road, Chaoyang District, Beijing 100101, China

e-mail: wanghm@igsnrr.ac.cn

M. Zhao

School of Social Sciences, Tsinghua University, Haidian District, Beijing 100084, China root dynamics to gradients in the soil moisture and solar radiation. The shrubs included three evergreen species, Loropetalum chinense, Vaccinium bracteatum, and Adinandra millettii, and three deciduous species, Serissa serissoides, Rubus corchorifolius, and Lespedeza davidii. Results We observed that variations in the annual fine root production and turnover among species were significant in the deciduous group but not in the evergreen group. Notably, $V$. bracteatum and $S$. serissoides presented the greatest responses in terms of root phenology to gradients in the soil moisture and shading: high-moisture habitat led to a decrease and shade led to an increase in fine root production during spring. Species with smaller fine roots of the $1^{\text {st }}+2^{\text {nd }}$-order diameter presented more sensitive responses in terms of fine root phenology to a soil moisture gradient. Species with a lower fine root carbon- to nitrogen ratio exhibited more sensitive responses in terms of fine root annual production to shading. Soil moisture and shading did not change the annual fine root production as much as the turnover rate.

Conclusions The fine root dynamics of some understory shrubs varied significantly with soil moisture and solar radiation status and may be different from tree species. Our results emphasize the need to study the understory fine root dynamics in the achievement of a complete understanding of the overall belowground carbon cycling in a forest ecosystem, particularly ecosystems in which the understory fine root highly contributes to the belowground biomass.

Keywords Shrub species $\cdot$ Root production . Phenology · Turnover $\cdot$ Soil moisture $\cdot$ Shading 


\section{Introduction}

Fine root dynamics is a critical component of global terrestrial carbon cycles (Norby and Jackson 2000). Shrubs make substantial contributions to the overall species diversity in the terrestrial ecosystem. Therefore, knowledge of the fine root production, phenology, and turnover rate of shrubs is critical to understanding how the carbon cycle of terrestrial ecosystem is affected by climate change.

Generally, the fine root life span of a shrub species increases with increasing root order (Valenzuela-Estrada et al. 2008). For some shrub species, the turnover rate of the first two order roots could be twice as high as that of the third order roots (Huang et al. 2010). Despite the endogenous cues, exogenous factors are important for controlling the fine root dynamics and the effects of exogenous factors on fine root dynamics have been received increasingly attention because of the expected climate changes (Kitajima et al. 2010). Previous studies have correlated fine root production with water regimes in water-limited shrublands (Peek et al. 2005; Palacio and Montserrat-Martí 2007; Padilla et al. 2015), and the effects of the soil moisture on the fine root dynamics have been reported to be species specific (Wilcox et al. 2004). Shading is another exogenous factor regulating fine root dynamics because root growth and turnover are correlated with photosynthetically active radiation (Fitter et al. 1998; Fitter et al. 1999; Volder et al. 2007). Although temperature and solar radiation are commonly linked during shading, Edwards et al. (2004) combined soil warming with canopy shading treatments and concluded that root turnover was significantly affected by solar radiation, but not temperature. However, the majority of relevant studies have investigated the consequences of endogenous or exogenous factors on the fine root dynamics of trees in forest ecosystems or of shrubs from shrublands. Our current understanding of how endogenous or exogenous factors regulate the root dynamics of understory vegetation in forest ecosystems is limited, despite that the roots of the understorey vegetation influences the variation in fine root production on a global scale (Finér et al. 2011). There is a particularly limited understanding of whether the fine root production, phenology, and turnover rate of understory vegetation present different responses to gradients in soil moisture and shading.

We selected a suite of study sites that represent habitats with gradients of soil moisture and solar radiation.
These gradients across the sites allow us to assess the role of changes in the soil moisture and shading in the fine root production, phenology, and turnover rate among six shrubs in a subtropical forest from China. Three of the investigated species are evergreen, whereas the other three species are deciduous. Although soil depth could have a major influence on fine root dynamics due to the variations in soil microenvironment (Aerts et al. 1989; Baddeley and Watson 2005), shallow roots were responsible for the majority of total annual fine root production and mortality (Hendrick and Pregitzer 1996). Therefore, we focused on the fine roots in top soil layer in this study. Our primary objectives were (1) to examine the variations in the fine root production phenology, annual production, and turnover rate among these subtropical shrub species or groups (deciduous vs. evergreen) and (2) to determine whether interspecies variations in root traits, such as diameter and carbon to nitrogen ratio, lead to predictable degrees of sensitivity in their responses, such as fine root production phenology, annual production, and turnover rate, to changes in the soil moisture and shading.

\section{Materials and methods}

Study site and experimental design

This study was conducted at the Qianyanzhou Ecological Station $\left(26^{\circ} 44^{\prime} 39^{\prime \prime} \mathrm{N}, 115^{\circ} 03^{\prime} 33^{\prime \prime} \mathrm{E}\right.$, at an elevation of $102 \mathrm{~m}$ above sea level) in Jiangxi Province in southeastern China. The station is approximately $204 \mathrm{hm}^{2}$ and has a typical subtropical climate. The mean annual temperature is $17.9^{\circ} \mathrm{C}$, with a minimum mean daily temperature of $6.4^{\circ} \mathrm{C}$ in January and a maximum of $28.8^{\circ} \mathrm{C}$ in July. The mean annual precipitation is $1489 \mathrm{~mm}$, and most of the precipitation occurs between March and June. The year is divided into four seasons, spring (March, April, and May), summer (June, July, and August), autumn (September, October, and November), and winter (December, January, and February), according to the meteorological definition of the seasons (Trenberth 1983). The soil is classified as Typic Dystrudepts by the USDA system (Wen et al. 2010).

The zonal vegetation at the station is a subtropical evergreen broad-leaved forest. Before the 1980's, the zonal vegetation had nearly disappeared due to deforestation. The dominant vegetation was grassland and 
scattered shrubland, and severe soil degradation had occurred. In 1983, widespread reforestation was implemented to combat the soil degradation. The needleleaf forest was dominated by Pinus elliottii, Pinus massoniana, and Cunninghamia lanceolata. The P. massoniana forest has a shrubby understorey dominated by six sun and drought-tolerant species, namely Loropetalum chinense, Vaccinium bracteatum, Adinandra millettii, Serissa serissoides, Rubus corchorifolius, and Lespedeza davidii. The first three species are evergreen with leathery leaves, and the remaining three species are deciduous with papery leaves. For the evergreen species, the longevity of leaves is generally more than one year and no marked thinning of the foliage occurs at any time. For the deciduous species, the amount of foliage becomes conspicuously thin during the leaf drop period (mainly in autumn and winter). Because the longevity of leaves is generally of about one year, the deciduous plants are never entirely leafless.

In a two-factorial plot design in which the factors are shading and the water moisture regime, four study plots with a size of $20 \mathrm{~m} \times 20 \mathrm{~m}$ size were established. The four plots were selected along two mountain slopes with similar soil nutrient (Table S1), soil texture (sandy loam), slope $\left(\sim 15^{\circ}\right)$ and aspect (northwest). One mountain slope (non-shaded) was located in a forest gap (0.32 ha). The other mountain slope (shaded) was located in an ambient $P$. massoniana mountain slope. The two mountain slopes were approximately $2 \mathrm{~km}$ apart. For each mountain slope, two plots with the distance of approximately $30 \mathrm{~m}$ were established at the mountain ridge and at the mountain foot. For the non-shaded slope, the P. massoniana was completely destroyed by a snowstorm in 2008, and from then, the understory shrubs grew in a fully open area. By 2013, there was a heavy growth of the understory vegetation and the dense understory was nearly impenetrable. The canopy cover of the shaded slope was $70 \%$, with spherical densiometer measurements (Lemmon 1956).

The soil moisture regime was determined by the slope position. We assessed the monthly gravimetric soil moisture by extracting 10 soil cores (diameter of $5.5 \mathrm{~cm}$ and depth of $10 \mathrm{~cm}$ ) from random locations per plot during the period January 2013-December 2013. Simultaneously with the soil moisture investigation, monthly soil temperature in the $0-10 \mathrm{~cm}$ layer was measured with a hand-held digital thermometer. The plots at the mountain ridge had a consistently lower soil moisture content than those at the mountain foot throughout the year (Fig. S1a). The mountain foot increased the soil moisture content by $42.2 \%$. Therefore, a low-soil -moisture habitat occurred at the mountain ridge plots, and a high-soil-moisture habitat occurred at the mountain foot plots. The mountain position did not change the soil temperature (Fig. S1b). Shaded and nonshaded contrasting habitats were obtained by comparing the plots in the forest gap slope with those in the ambient P. massoniana slope. The flux densities of photosynthetically active radiation (PAR) above and below the canopy were measured using quantum sensors (LI-COR Inc., Lincoln, NE, USA). One LI-190 SA quantum sensor was positioned at $41 \mathrm{~m}$ and three LI-191 SA quantum sensors were mounted at $1.5 \mathrm{~m}$. Shading reduced photosynthetic photon flux density (PPFD) by $86.7 \%$. The soil moisture tended to be lower in the shaded plots than in the non-shaded plots (Fig. S2a). The higher soil moisture in the non-shaded plots is likely due to the reduced tree root density and thus the reduced transpiration of soil water (Gray et al. 2002). Soil temperature differences did not exist between the shaded and non-shaded plots (Fig. S2b).

Fine root dynamics

In this study, the root dynamics were measured using horizontal rhizotrons to identify the fine root by species. Based on our preliminary observations, c. $63 \%$ of understory fine roots centered within the top $10 \mathrm{~cm}$ of P. massoniana forest soil. Therefore, we installed the horizontal rhizontrons at a soil depth of $5 \mathrm{~cm}$ to represent the average fine root dynamics in the $0-10 \mathrm{~cm}$ layer. In midApril 2012, 10 rhizotrons were installed for each of the six dominant shrub species, L. chinense, $V$. bracteatum, A. millettii, S. serissoides, R. corchorifolius, and L. davidii, in each plot, for a total of 240 windows $(6$ species $\times 10$ replications $\times 4$ plots). Separate adult individuals of each species were randomly selected. Three or four rhizotrons were installed for each individual plant. Root age had a strong effect on the risk of fine-root mortality (Wells et al. 2002). To enhance the comparability across treatments, the lateral roots were pruned to ensure the studied roots were new growth (Liu et al. 2015). A lateral fourth-order root was identified and all of the finer lateral branches were pruned. A Plexiglas acrylic window of $10 \mathrm{~cm} \times 10 \mathrm{~cm}$ was then carefully placed on the pruned lateral root. Finally, to protect the roots from light and variations in temperature, a black plastic bag containing 
the total volume of original soil above the roots was placed on the window. During each observation, each window was photographed using a digital camera (D7100; Nikon, Tokyo, Japan). A more detailed description of the installation of horizontal rhizotrons was described in Xia et al. (2010).

In our experiment, image collection began in June 2012 and ended in December 2013. The imaging occurred at approximately one-month intervals. Although the rhizotron method resulted in a limited disturbance of the soil environment (Xia et al. 2010), we report the fine root dynamics for the year 2013 excluding 2012 to ensure that the fine roots of the first three orders were well developed. Because the roots of the first two orders play a major role in root turnover and carbon and nitrogen flow from plant to soil (Huang et al. 2010), our observations of fine roots were limited to first- and second-order roots. It should be noted that because it is difficult to photograph the windows with the same angles, the rhizotron production cannot be accurately standardized by soil area (e.g. in unit of root length $\mathrm{m}^{-2}$ ). The previous studies showed that there was a strong positive correlation between the number and the length of fine roots (Leppälammi-Kujansuu et al. 2014) and the fine root production and turnover rates calculated using the root length were similar to those calculated using the root number (McCormack et al. 2014). Therefore, the fine root production and turnover rate were calculated using the numbers of roots produced instead of the root length (West et al. 2004; McCormack et al. 2014). The annual fine root production (roots per window) divided by the average fine root standing crop (roots per window) yielded the fine root turnover rate. Roots were counted as newly produced when they first appeared, and their mortality was determined when the roots were fractured, shriveled visually, or disappeared. Averaged across all six species, c. $40 \%$ of the installed rhizotrons contained no new roots or not well-developed new roots. Termite runs and frass were detected occasionally in the rhizotrons during the later observations. To the end, the lost observations due to termite disturbance occurred almost equally across the species and plots. The lost observation due to termite disturbance accounted for c. $20 \%$ of the total rhizotrons. Therefore, $40 \%$ of the installed rhizotrons with well-developed root systems were used in the final analysis. The observed fine roots number varied with the species and ranged from 168 to 540 . In total this analysis included 1752 fine roots.
Fine root traits

Various root traits were assessed for each species across four blocks $(n=4)$. The roots from six plants for each species in each plot were collected at a depth of 0 $10 \mathrm{~cm}$ in May 2012. The plants were different from those for the fine root dynamics observation. The excavated roots and soil were packed in plastic bags, and all of the root segments were rinsed and cleaned with deionized water $\left(4^{\circ} \mathrm{C}\right)$ after transport to the laboratory. The first- and second-order roots of the six shrubs were dissected. All of the living rootlets of a soil sample were analyzed to determine their mean root diameter and specific root length (SRL, in $\mathrm{m} \mathrm{g}^{-1}$ ) using a scanner and a WinRhizo (Regent Instruments Inc., Québec, Canada) visual analysis system. The fine root segments were carefully removed from the glass and oven-dried $\left(65^{\circ} \mathrm{C}\right.$ for $72 \mathrm{~h}$ ) to a constant weight to determine their mass. The first- and second-order roots were combined to measure their carbon $(\mathrm{C})$ and nitrogen $(\mathrm{N})$ concentrations using a CN-element analyzer (Elementar VarioMax CN, Mt. Laurel, NJ, USA).

\section{Statistical analyses}

The first two orders roots are prone to be similar in terms of mycorrhizal colonization and diameter (ValenzuelaEstrada et al. 2008). Therefore, the first two order roots were lumped together for all the six shrub species. To ensure sufficient rhizotron replications (at least six), we did not analyze the interaction effect of shading and soil moisture regime. We pooled the data from the ambient P. massoniana mountain slope and forest gap slope to examine the shading effect, and the data from the mountain ridge and mountain foot to examine the effects of soil-moisture regime. The annual fine root production and the turnover rate were pooled across all of the treatments to test their variations among the different species. We used a one-way ANOVA and multiple comparison procedure (Tukey's HSD test) to assess differences in terms of the fine root diameter, specific root length, $\mathrm{C}: \mathrm{N}$ ratio, annual production and annual turnover rate among the studied shrub species. Significant differences were assessed at the $P<0.05$ level.

The temporal patterns of the fine root production (number of new roots per month) were depicted according to the four seasons. The changes in the amplitudes (CAs) of the fine root production and turnover rate 
among the treatments were calculated for each species. In this study, CA is used to quantify the magnitude of changes in the fine root dynamics among habitats within species. Greater CA values indicate that the fine root dynamics have higher degrees of sensitivity to the habitats. The within-species values for the $\mathrm{CA}$ of fine root annual production $\left(\mathrm{CA}_{\mathrm{AP}}\right)$ and $\mathrm{CA}$ of the turnover rate $\left(\mathrm{CA}_{\mathrm{T}}\right)$ among the habitats were calculated as follows:

$\mathrm{CA}_{\mathrm{AP}}\left(\mathrm{CA}_{\mathrm{T}}\right)=($ large value - small value $) /$ small value $(1)$

The sum of the CA of the monthly production $\left(\sum \mathrm{CA}_{\mathrm{MP}}\right)$ among habitats within species was calculated as follows:

$\sum \mathrm{CAMP}=\sum_{i=J a n}^{n} \frac{(\mathrm{Li}-\mathrm{Si})}{S i}$

where $\mathrm{L}_{i}$ and $\mathrm{S}_{i}$ are the large and small values of obtained on month $i$ ( $i=$ Jan., Feb., Mar., ... $n$ ) among the treatments. $\sum \mathrm{CA}_{\mathrm{MP}}$ represents the degrees of sensitivity that the fine root production phenology exhibits in response to the habitats. A Pearson correlation was used to test the relationship between the variation in the sensitivity of the properties of fine root dynamic $\left(\mathrm{CA}_{\mathrm{AP}}, \mathrm{CA}_{\mathrm{T}}\right.$, and $\left.\sum \mathrm{CA}_{\mathrm{MP}}\right)$ and the fine root $1^{\text {st }}+2^{\text {nd }}$-order diameter (significantly correlated with the $1^{\text {st }}+2^{\text {nd }}$-order SRL, $\mathrm{R}=-0.873, P<0.01)$ and $\mathrm{C}: \mathrm{N}$ for the soil moisture and shaded treatments. All of the statistical analyses were performed using the software SPSS Version 10.0 (SPSS Inc., Chicago, IL, USA).

\section{Results}

Variation across species

The shrub species exhibited significant differences in root traits (Table 1). The $1^{\text {st }}+2^{\text {nd }}$-order specific root length ranged from $91.0 \mathrm{~m} \mathrm{~g}^{-1}$ in $L$. chinense and $183.0 \mathrm{~m} \mathrm{~g}^{-1}$ in L. davidii to $507.2 \mathrm{~m} \mathrm{~g}^{-1}$ in $S$. serissoides and $550.9 \mathrm{~m}$ $\mathrm{g}^{-1}$ in $V$. bracteatum, whereas the $1^{\text {st }}+2^{\text {nd }}$-order diameter was more constrained and ranged from $0.26 \mathrm{~mm}$ in $V$. bracteatum to $0.57 \mathrm{~mm}$ in L. chinense (Table 1). The $\mathrm{C}: \mathrm{N}$ varied approximately two-fold across the species, ranging from 65.88 in $V$. bracteatum to 34.52 in $R$. corchorifolius (Table 1). Significant variations in the root traits were found among the species in both the evergreen and deciduous groups (Table 1).
The shrub species also presented differences in the annual fine root production and turnover (Fig. 1). S. serissoides had a significantly larger annual production than the other five species. The annual fine root production varied from 1.8-fold to four-fold among the deciduous species, but variations of only 1.4-fold to 2.9fold were obtained from the comparison of any deciduous species with any evergreen species. The turnover in $S$. serissoides $(\sim 2.0)$ was higher than that in $V$. bracteatum, A. millettii, and L. davidii $(\sim 1.0)$. The among-species variations in the annual fine root production and turnover were significant in the deciduous group but not in the evergreen group.

\section{Effects of soil moisture and shading}

The effects of soil moisture and shading on the phenology of fine root production varied among species (Figs. 2 and 3). Some of the species, such as $V$. bracteatum from the evergreen group and $S$. serissoides from the deciduous group, presented the greatest changes in root phenology. The fine root production of these two species tended to be decreased by high moisture and increased by shade in the spring. However, the fine root production patterns were different between these two species. $V$. bracteatum exhibited a bimodal pattern in the low-soil-moisture and shade habitats, with a peak in the spring and another peak in the summer, but displayed a concentrated modal pattern in the high-soil-moisture and non-shaded habitats, with peak production occurring in the summer. In the case of $S$. serissoides, high-soil-moisture and non-shaded habitats changed the fine root production from a distributed pattern to a concentrated pattern (peak in summer). These results indicate that high-soil-moisture and shade habitats had contrary effects on the fine root production pattern exhibited by these two species. A. millettii and $R$. corchorifolius displayed moderate changes in root phenology, including no changes in the root production pattern but slight changes during two or three sampling periods. Other species, such as $L$. chinense from the evergreen group and $L$. davidii from the deciduous group, were not sensitive to changes in root phenology. The root phenology of these two species presented bimodal and distributed modal patterns, respectively.

The habitats did not change the annual fine root production as greatly as the turnover rate (Figs. 4 and 5). The high-soil-moisture habitat marginally significantly decreased the annual production of $L$. davidii 
Table 1 Variations in the fine root 1st +2 nd-order diameter, specific root length (SRL), and C:N ratio among six shrub species. The mean values are followed by the standard errors. Different letters indicate significant differences at $P<0.05$. The sample size was 200 for each root order

\begin{tabular}{lllll}
\hline Groups & Species & Diameter $(\mathrm{mm})$ & SRL $\left(\mathrm{m} \mathrm{g}^{-1}\right)$ & C:N \\
\hline Evergreen & Vaccinium bracteatum & $0.26( \pm 0.015) \mathrm{c}$ & $550.9( \pm 99.76) \mathrm{a}$ & $65.88( \pm 0.50) \mathrm{a}$ \\
& Adinandra millettii & $0.45( \pm 0.005) \mathrm{b}$ & $218.0( \pm 12.56) \mathrm{b}$ & $42.85( \pm 0.28) \mathrm{c}$ \\
& Loropetalum chinense & $0.57( \pm 0.006) \mathrm{a}$ & $91.0( \pm 3.28) \mathrm{b}$ & $42.43( \pm 0.22) \mathrm{c}$ \\
Deciduous & Rubus corchorifolius & $0.30( \pm 0.011) \mathrm{c}$ & $445.9( \pm 56.62) \mathrm{a}$ & $34.52( \pm 0.17) \mathrm{d}$ \\
& Serissa serissoides & $0.33( \pm 0.002) \mathrm{c}$ & $507.2( \pm 12.11) \mathrm{a}$ & $48.22( \pm 0.23) \mathrm{b}$ \\
& Lespedeza davidii & $0.47( \pm 0.034) \mathrm{b}$ & $183.0( \pm 5.84) \mathrm{b}$ & $41.43( \pm 0.68) \mathrm{c}$ \\
\hline
\end{tabular}

$(P=0.059)$ and significantly inhibited the turnover rate of $V$. bracteatum $(P=0.041)$. The effects of shading on the annual fine root production in the six shrub species were not statistically significant. However, the effects of shading on the turnover were marginally significant in $A$. millettii $(P=0.059)$ and significant in $R$. corchorifolius $(P=0.04)$. Both species showed lower turnover rates in shade. However, the turnover rate of $R$. corchorifoliuswas almost twice as high in the non-shaded habitats as in the shaded habitats.

Relationship of the sensitivity of fine root dynamics to the endogenous traits of fine roots

Table 2 displays the association between the sensitivities of the fine root dynamics to the soil moisture regime and shading and the fine root endogenous traits across species. The analysis of the soil moisture regime revealed

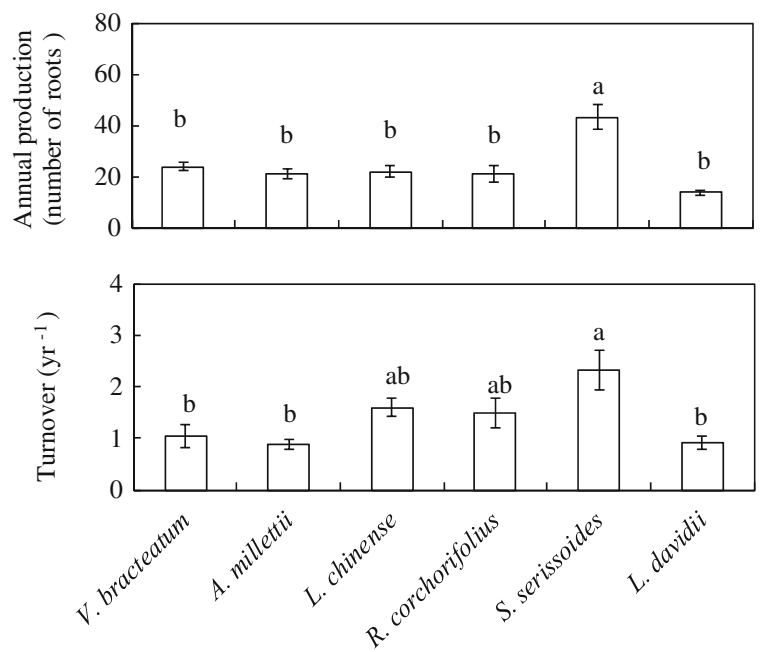

Fig. 1 Fine root annual production and turnover in six shrub species. Different letters indicate significant differences at $P<0.05$. Error bars represent the standard error of the mean that the fine root $1^{\text {st }}+2^{\text {nd }}$-order diameter was negatively associated with the sensitivity degree of the fine root production phenology but not with the sensitivity degree of the annual fine root production. The analysis of the shading habitats revealed that the sensitivity degree of the fine root production phenology was not related to the fine root traits and that the sensitivity of the fine root annual production was negatively related to the fine root $\mathrm{C}: \mathrm{N}$ ratio. The sensitivities of fine root turnover to soil moisture regime and shading were not significantly associated with any of these two endogenous traits of fine roots.

\section{Discussion}

Fine root production and turnover among species

Similar to the results from tree species (McCormack et al. 2014), our order-based study showed that shrub species presented significant differences in the root growth. Across some temperate tree species, the diameter of the lowest two root orders significantly explained the differences in fine root lifespan (McCormack et al. 2012). Our results did not fully support this conclusion because $S$. serissoides from the deciduous group and $V$. bracteatum from the evergreen group presented statistically comparable root diameters and specific lengths but different turnovers and because the three evergreen species presented difference in root diameter but had comparable turnover. The relative narrow range of root diameter in our study may help in the lack of association between fine root diameter and turnover. In the deciduous group, $S$. serissoides with a lower diameter but higher SRL and C:N had a larger annual production and a higher turnover rate. Higher fine root production coupled with rapid turnover rates was observed for some 

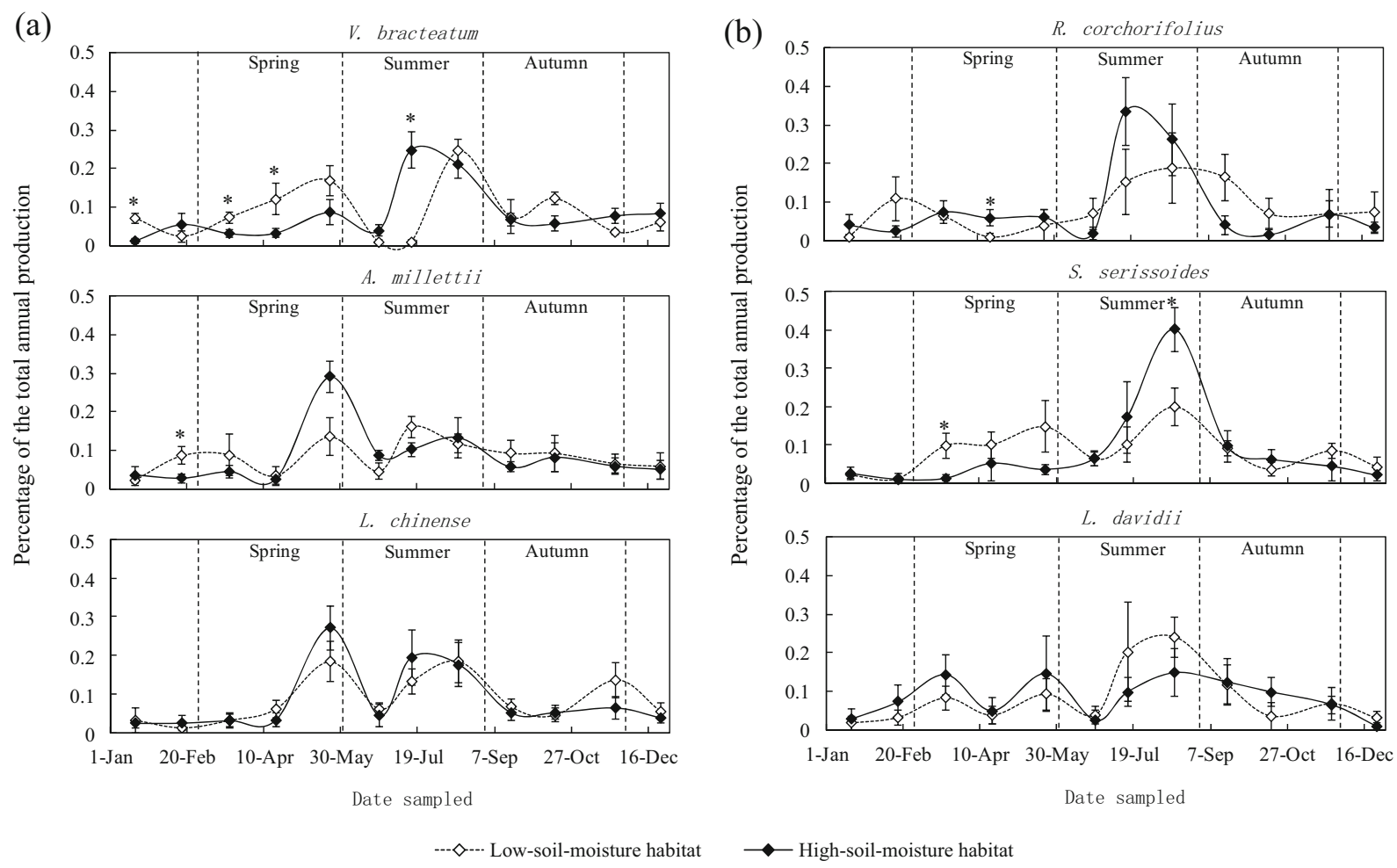

Fig. 2 Patterns of fine root production phenology in evergreen (a) and deciduous (b) shrubs under low and high soil moisture habitats. The mean value is shown with the standard error $( \pm \mathrm{SE}) .{ }^{*}$ Indicates a significant difference at $P<0.05$

temperate and tropical tree species (Valverde-Barrantes et al. 2007; McCormack et al. 2014).

Observations from our study further revealed that the variations in the annual fine root production and turnover among shrub species were significant in the deciduous group but not significant in the evergreen group. Moreover, the range of variation in the annual fine root production between the three deciduous species exceeded the difference between any of the deciduous species and any of the evergreen species. Our narrowscale species comparison indicates that deciduous shrub species are likely to be more important than evergreen shrub species for obtaining variations in the total root population across the forest ecosystem in the study area. Our results further indicate that the evergreen and deciduous grouping level may be not sufficiently small to predict the root dynamics. This finding is consistent with the results reported by Vogt et al. (1996), who demonstrated that temperature variables perform well in explaining the changes in the root dynamics at the level of the individual climatic forest type but not at the evergreen and deciduous grouping level.
The fine root dynamics fluctuated seasonally, with growth generally peaking during the warmer months (Burke and Raynal 1994; Tierney et al. 2003; Kitajima et al. 2010). The root phenology has been paralleled to the aboveground phenology in a mature oak stand (Joslin et al. 2001). During winter, the remained few leaves of the decidous species may be responsible for the low fine root production. During the course of this study, we did not observe the exact aboveground phenology pattern. However, the root and shoot phenology has been suggested to be closely coupled in grasslands and tundra and less coupled in shrubland and forest (Steinaker and Wilson 2008). The patterns of the fine root production phenology of the examined shrub species were diversified, presenting bimodal, concentrated and distributed modal patterns. The diversified root phenology is likely to due to the variations in seasonal carbon allocation among species (Oechel et al. 1972; Mooney and Chu 1974). A concentrated modal pattern was observed for the tree species Eucalyptus urophylla (Xu et al. 2013) and the Mytilaria laosensis stand with fewer understories (Huang et al. 2014) in the subtropical region of China. Although bimonthly sampling of fine 
(a)

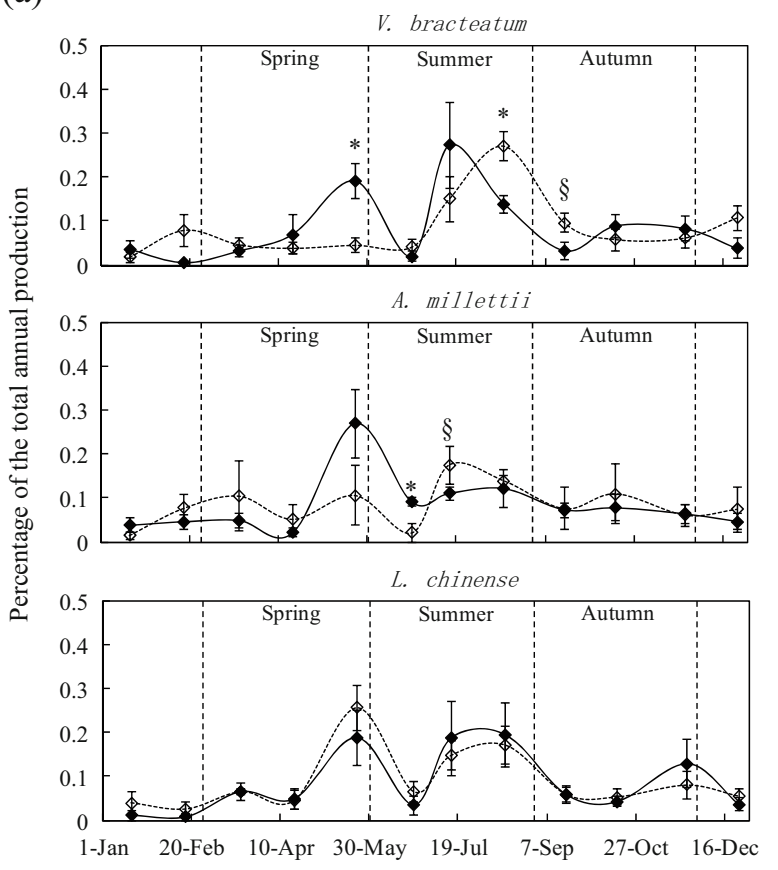

(b)

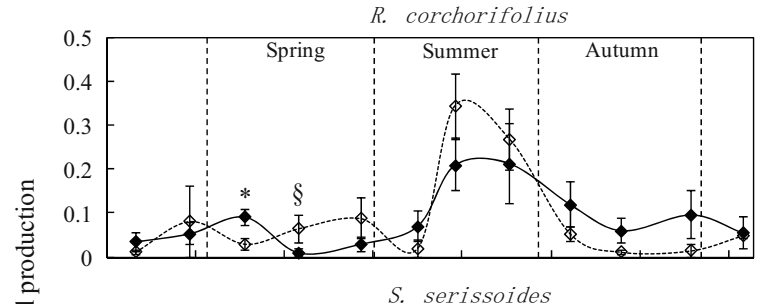

Date sampled

$\longrightarrow$ Shaded $\cdots \diamond$. Non-shaded

Fig. 3 Patterns of fine root production phenology in evergreen (a) and deciduous (b) shrubs under shaded and non-shaded treatments. The mean value is shown with the standard error $( \pm \mathrm{SE}) .{ }^{*}$ Indicates a significant difference at $P<0.05,{ }^{\S}$ indicates a significant difference at $P<0.1$
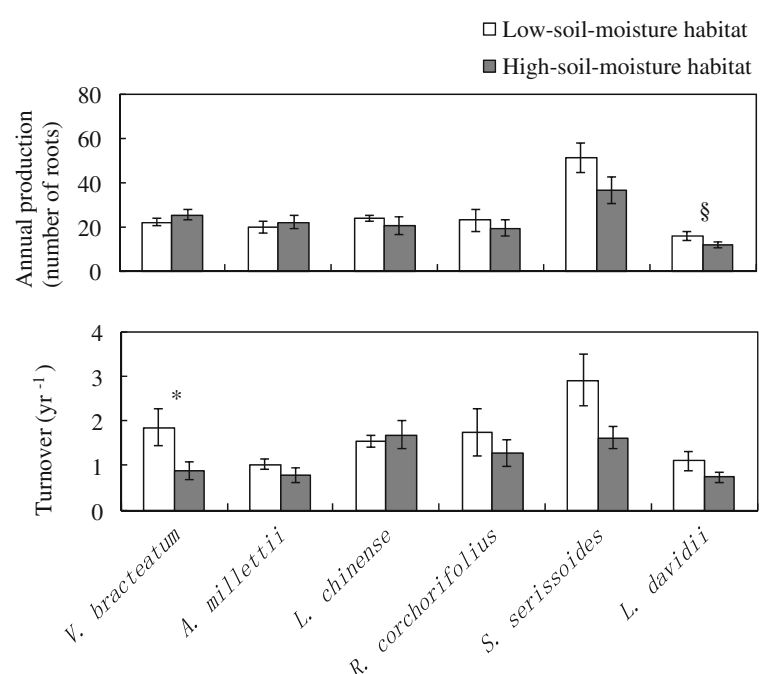

Fig. 4 Effects of soil moisture habitat on fine root annual production and turnover in six shrub species. Six rhizotron replications were used for the analysis. Error bars represent the standard error of the mean. ${ }^{*}$ Indicates a significant difference at $P<0.05$, $\S_{\text {indicates a marginally significant difference at } P<0.1}$
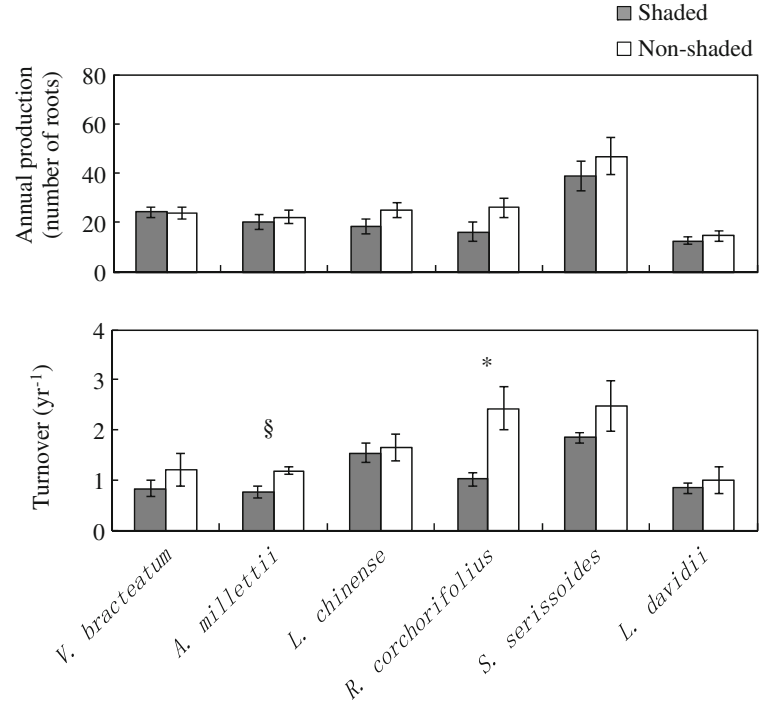

Fig. 5 Effects of shading on fine root annual production and turnover in six shrub species. Six rhizotron replications were used for the analysis. Error bars represent the standard error of the mean. ${ }^{*}$ Indicates a significant difference at $P<0.05,{ }^{\S}$ Indicates a marginally significant difference at $P<0.1$ 
Table 2 Pearson correlation results between the variation sensitivity of the fine root dynamic properties, the fine root $1 \mathrm{st}+2 \mathrm{nd}-$ order diameter and the $\mathrm{C}: \mathrm{N}$ ratio to the soil moisture and shaded treatments $(n=6)$. The $\sum \mathrm{CA}_{\mathrm{MP}}, \mathrm{CA}_{\mathrm{AP}}$ and $\mathrm{CA}_{\mathrm{T}}$ are the sum of the $\mathrm{CA}$ of the monthly production, the $\mathrm{CA}$ of fine root annual production, and the $\mathrm{CA}$ of the turnover rate

\begin{tabular}{|c|c|c|c|c|c|}
\hline \multirow[t]{2}{*}{ Treatment } & \multirow[t]{2}{*}{ Variation sensitivity } & \multicolumn{2}{|c|}{$1 \mathrm{st}+2$ nd-order diameter } & \multicolumn{2}{|c|}{$\mathrm{C}: \mathrm{N}$ ratio } \\
\hline & & $\mathrm{R}$ & $P$ & $\mathrm{R}$ & $\mathrm{P}$ \\
\hline \multirow[t]{3}{*}{ Soil moisture } & $\sum \mathrm{CA}_{\mathrm{MP}}$ & -0.853 & 0.031 & 0.536 & 0.273 \\
\hline & $\mathrm{CA}_{\mathrm{AP}}$ & 0.018 & 0.973 & 0.014 & 0.980 \\
\hline & $\mathrm{CA}_{\mathrm{T}}$ & -0.753 & 0.084 & 0.794 & 0.059 \\
\hline \multirow[t]{3}{*}{ Shading } & $\sum \mathrm{CA}_{\mathrm{MP}}$ & -0.765 & 0.076 & 0.091 & 0.863 \\
\hline & $\mathrm{CA}_{\mathrm{AP}}$ & 0.065 & 0.903 & -0.888 & 0.018 \\
\hline & $\mathrm{CA}_{\mathrm{T}}$ & -0.608 & 0.200 & -0.491 & 0.323 \\
\hline
\end{tabular}

roots performed in the study conducted by $\mathrm{Xu}$ et al. (2013) and the inclusion of understory fine roots in the study performed by Huang et al. (2014) may reduce the resolution of the patterns identified for the tree species, our findings and these two results collectively suggest that the fine root production phenology may vary significantly among growth forms, such as trees and shrubs in the study area. Similarly, Steinaker and Wilson (2008) found that woody species in an aspen forest and grass species in an adjacent native grassland presented differences in their timing of belowground production. Consistent with the above-mentioned results, a recent study observed that the different fine root production phenology among plant growth forms, such as trees, shrubs, and grass, yielded a dramatic fluctuation of the fine root production peak-timing among different forest types on the same study site (Liu et al. 2014). The different patterns between growth forms would cast into doubt the knowledge of the total belowground producer phenology and thus the temporal variation in the belowground carbon cycling based only on tree species traits.

The interspecific differences in root traits help in explaining the spatial variation in root traits (Liu et al. 2010). However, the variation in the total production and turnover rates from year to year has generally been recorded within a single tree species and/or stand (Burke and Raynal 1994; Rytter 2013; Leppälammi-Kujansuu et al. 2014), and the interannual variability in the fine root turnover rate was equal to or greater than the difference among species obtained for some temperate tree species (McCormack et al. 2014). In addition, soil depth could also have a major influence on the fine root dynamics of shrubs (Aerts et al. 1989; Baddeley and Watson 2005). Therefore, the long-term trend requires further study to identify the average variation in the annual production and turnover rates along the soil profile among the studied shrub species.

Effects of the soil moisture gradient and shading on the fine root dynamics

The fine root production of $V$. bracteatum and $S$. serissoides in response to changes in the soil water content suggests that a low soil moisture habitat reduced the fine root production during most summers but increased the fine root production during the spring. During the study year of 2013, the study site is characterized by a typical episodic summer drought and plenty of rainfall in the spring (Fig. S3). Therefore, too much soil moisture in the spring and a lower soil moisture in the summer would inhibit root growth. The fine root production phenology of $V$. bracteatum and $S$. serissoides significantly varied with the gradients in the soil moisture. However, the differences did not lead to a significant variation in the annual fine root production of these two species because the lower fine root production obtained with a high-soilmoisture habitat during spring was compensated for by the higher growth during summer. Rytter (2013) studied the fine root phenology in two deciduous species, Alnus incana and Salix viminalis, and suggested that their Nfixing capacity would result in the fine root phenology of $A$. incana having a less pronounced response to water. This finding is supported by the result that the fine root phenology of the leguminous $L$. davidii in our study was less sensitive to the soil moisture gradient.

Because our experiment compared the annual fine root production from a high-soil-water habitat and a low-soil-water habitat, our results paralleled those 
obtained from experiment across a precipitation gradient with a similar soil texture. The apparent resilience of the annual fine root production to a soil water gradient matches the findings reported by Joslin et al. (2000) for a mature deciduous forest obtained on a throughfall displacement experiment. In contrast, Hertel et al. (2013) showed that precipitation exhibited a strong explanatory power for the variations in the fine root productivity obtained for 12 mature Fagus sylvatica forests across a precipitation gradient. The discrepancy may be due to differences in climate. The study sites used by Joslin et al. (2000) and us have an annual precipitation of approximately $1400 \mathrm{~mm}$. In contrast, Hertel et al. (2013) conducted their study across a precipitation gradient from 820 to $543 \mathrm{~mm} \mathrm{yr}^{-1}$. This relatively low precipitation is likely to introduce a water-limited climate for plants and thus results in a strong response in terms of fine root production. Moreover, the six shrub species are drought-tolerant. This fact may also help in the apparent resilience of the annual fine root production to a soil water gradient in our study.

A global-scale observation and an experiment in which the site water is manipulation showed that the root turnover rates are independent of the water availability (Gill and Jackson 2000; Rytter 2013). Our results support the suggestions that the effects of soil moisture on root turnover appear to be species specific (Anderson et al. 2003). In the present study, high-soil-moisture habitat was found to significantly inhibit the turnover rate of $V$. bracteatum, whereas the soil moisture did not affect the turnover rate of the other five species.

Shading exerted significant effects on the fine root production phenology of $V$. bracteatum and $S$. serissoides by reducing the fine root production in most summers but increasing the fine root production in the spring. This is likely due to the relatively low soil moisture content in the shaded plot (Fig. S2a). Similar to the soil moisture treatments, relatively lower soil moisture may increase fine root growth in the spring but decrease fine root growth in the summer. No significant variation in the annual fine root production was observed because the lower fine root production obtained in the non-shaded habitat during spring was compensated for by the higher growth obtained during the summer, similarly to the results obtained for the soil moisture gradient. Contrary to our expectation, the annual fine root production of the six sun shrub species was not sensitive to shading. Given the lack of continuous observation it is unclear if the solar radiation gradient affected the annual fine root production during the earlier stage after the forest gap formation. We did not have sufficient data to analyze the interactive effect of shading and the soil moisture content, but this topic deserves further attention.

Some of the investigated species, such as $V$. bracteatum from the leathery-leaved evergreen group and $S$. serissoides from the papery-leaved deciduous group, presented the greatest sensitivity in terms of fine root phenology to the soil moisture gradient, indicating the substantial variation in fine root phenology sensitivity within the leaf texture categories. Instead, we found that the shrub species with finer roots presented greater sensitivity in terms of fine root production phenology to changes in the soil moisture. Our results provide evidence that variations in the fine root demography may present a greater resolution in parallel to the habitat environmental differences than the leaf characteristics, a finding that was previously suggested for sandhill tree species (Espeleta et al. 2009).

\section{Conclusions}

The fine root dynamics of different species components determines how forests may adapt to a changing climate as well as how the carbon cycle of a forest ecosystem is affected by climate change. We assessed the fine root production phenology, total fine root production and turnover among six understory shrub species in a subtropical climate and demonstrated links between specific-dependent environmental (soil moisture and shading) sensitivity and fine root traits (diameter, specific root length, and $\mathrm{C}: \mathrm{N}$ ratio). We observed that the fine root production phenology of the examined shrub species presented diversified patterns, including bimodal, concentrated, and distributed modal patterns. Moreover, the fine root phenology pattern of some shrubs varied significantly with changes in the soil moisture regime and solar radiation status. These results emphasize the need to study the understory fine root phenology to understand the temporary variation in the belowground carbon cycling. The variations in the annual fine root production and turnover observed among shrub species were significant in the deciduous group but not in the evergreen group, indicating that the evergreen and deciduous grouping level may not be sufficient to predict root dynamics. Our results further indicate that the degrees of sensitivity of the fine root dynamics to soil moisture and shading are more highly associated with the root traits, such as diameter and $\mathrm{C}: \mathrm{N}$ 
ratio, rather than the aboveground characteristics, such as leaf texture. Overall, to predict how anticipated global climate changes may affect the carbon flux, studies such as ours that examine the effects of environmental variables and fine root dynamics in understory vegetation are urgently needed in ecosystems where the understory fine roots contribute greatly to the below-ground biomass. It should be noted that we only examined the fine root dynamics in the top soil layer with the study period of one year, and the long-term trend along the soil profile requires further study to identify.

Acknowledgments We thank Dali Guo and Bitao Liu for their valuable comments regarding earlier versions of the manuscript. This work was funded by the National Key Basic Research Special Foundation Project (2012CB416903), the NSFC Projects of International Cooperation and Exchanges (31210103920), the National Natural Science Foundations of China (41101203), and the GanPo Distinguished Researcher Program.

Compliance with Ethical Standards The authors have declared that no potential conflicts of interest exist, no specific permissions were required for these activities and the field study did not involve endangered or protected species.

\section{References}

Aerts R, Berendse F, Klerk NM, Bakker C (1989) Root production and root turnover in two dominant species of wet heathlands. Oecologia 81:374-378

Anderson LJ, Comas LH, Lakso AN, Eissenstat DM (2003) Multiple risk factors in root survivorship: a 4-year study in Concord grape. New Phytol 158:489-501

Baddeley JA, Watson CA (2005) Influences of root diameter, tree age, soil depth and season on fine root survivorship in Prunus avium. Plant Soil 276:15-22

Burke MK, Raynal DJ (1994) Fine root growth phenology, production, and turnover in a northern hardwood forest ecosystem. Plant Soil 162:135-146

Edwards EJ, Benham DG, Marland LA, Fitter AH (2004) Root production is determined by radiation flux in a temperate grassland community. Glob Chang Biol 10:209-227

Espeleta JF, West JB, Donovan LA (2009) Tree species fine-root demography parallels habitat specialization across a sandhill soil resource gradient. Ecology 90:1773-1787

Finér L, Ohashi M, Noguchi K, Hirano Y (2011) Fine root production and turnover in forest ecosystems in relation to stand and environmental characteristics. For Ecol Manag 262: 2008-2023

Fitter AH, Graves JD, Self GK, Brown TK, Bogie DS, Taylor K (1998) Root production, turnover and respiration under two grassland types along an altitudinal gradient: influence of temperature and solar radiation. Oecologia 114:20-30
Fitter AH, Self GK, Brown TK, Bogie DS, Graves JD, Benham D, et al. (1999) Root production and turnover in an upland grassland subjected to artificial soil warming respond to radiation flux and nutrients, not temperature. Oecologia 120:575-581

Gill RA, Jackson RB (2000) Global patterns of root turnover for terrestrial ecosystem. New Phytol 147:13-31

Gray AN, Spies TA, Easter MJ (2002) Microclimatic and soil moisture responses to gap formation in coastal Douglas-fir forests. Can J For Res 32:332-343

Hendrick RL, Pregitzer KS (1996) Temporal and depth-related patterns of fine root dynamics in northern hardwood forests. $J$ Ecol 84:167-176

Hertel D, Strecker T, Müller-Haubold H, Leuschner C (2013) Fine root biomass and dynamics in beech forests across a precipitation gradient - is optimal resource partitioning theory applicable to water-limited mature trees? J Ecol 101:1183-1200

Huang G, Zhao X, Zhao H, Huang Y, Zou X (2010) Linking root morphology, longevity and function to root branch order: a case study in three shrubs. Plant Soil 336:197-208

Huang Z, Yu Z, Wang M (2014) Environmental controls and the influence of tree species on temporal variation in soil respiration in subtropical China. Plant Soil 382:75-87

Joslin JD, Wolfe MH, Hanson PJ (2000) Effects of altered water regimes on forest root systems. New Phytol 147:117-129

Joslin JD, Wolfe MH, Hanson PJ (2001) Factors controlling the timing of root elongation intensity in a mature upland oak stand. Plant Soil 228:201-212

Kitajima K, Anderson KE, Allen MF (2010) Effect of soil temperature and soil water content on fine root turnover rate in a California mixed conifer ecosystem. J Geophys Res 115: G04032

Lemmon PE (1956) A spherical densiometer for estimating forest overstory density. For Sci 2:314-320

Leppälammi-Kujansuu J, Salemaa M, Kleja DB, Linder S, Helmisaari H (2014) Fine root turnover and litter production of Norway spruce in a long-term temperature and nutrient manipulation experiment. Plant Soil 374:73-88

Liu G, Freschet GT, Pan X, Cornelissen JHC, Li Y, Dong M (2010) Coordinated variation in leaf and root traits across multiple spatial scales in Chinese semi-arid and arid ecosystems. New Phytol 188:543-553

Liu C, Xiang W, Lei P, Deng X, Tian D, Fang X, Peng C (2014) Standing fine root mass and production in four Chinese subtropical forests along a succession and species diversity gradient. Plant Soil 376:445-459

Liu B, Li H, Zhu B, Koide RT, Eissenstat DM, Guo D (2015) Complementarity in nutrient foraging strategies of absorptive fine roots and arbuscular mycorrhizal fungi across 14 coexisting subtropical tree species. New Phytol. doi:10. 1111/nph.13434

McCormack ML, Adams TS, Smithwick EAH, Eissenstat DM (2012) Predicting fine root lifespan from plant functional traits in temperate trees. New Phytol 195:823-831

McCormack ML, Adams TS, Smithwick EAH, Eissenstat DM (2014) Variability in root production, phenology, and turnover rate among 12 temperate tree species. Ecology 8:2224 2235

Mooney HA, Chu C (1974) Seasonal carbon allocation in Heteromeles arbutifolia a California evergreen shrub. Oecologia 14:295-306 
Norby RJ, Jackson RB (2000) Root dynamics and global change: seeking an ecosystem perspective. New Phytol 147:3-12

Oechel WC, Strain BR, Odening WR (1972) Tissue water potential, photosynthesis, C-labeled photosynthate utilization, and growth in the desert shrub Larrea divaricata. Cav Ecol Monogr 42(2):127--141

Padilla FM, de Dios MJ, Armas C, Pugnaire FI (2015) Effects of changes in rainfall amount and pattern on root dynamics in an arid shrubland. J Arid Environ 114:49-53

Palacio S, Montserrat-Martí G (2007) Above and belowground phenology of four Mediterranean sub-shrubs. Preliminary results on root-shoot competition. J Arid Environ 68:522533

Peek MS, Leffler AJ, Ivans CY, Ryel RJ, Caldwell MM (2005) Fine root distribution and persistence under field conditions of three co-occurring Great Basin species of different life form. New Phytol 165:171-180

Rytter R (2013) The effect of limited availability of $\mathrm{N}$ or water on $\mathrm{C}$ allocation to fine roots and annual fine root turnover in Alnus incana and Salix viminalis. Tree Physiol 33:924-939

Steinaker DF, Wilson SD (2008) Phenology of fine roots and leaves in forest and grassland. J Ecol 96:1222-1229

Tierney GL, Fahey TJ, Groffman PM, Hardy JP, Fitzhugh RD, Driscoll CT, Yavitt JB (2003) Environmental control of fine root dynamics in a northern hardwood forest. Glob Chang Biol 9:670-679

Trenberth KE (1983) What are the seasons? B Am Meteorol Soc 64:1276-1282

Valenzuela-Estrada LR, Vera-Caraballo V, Ruth LE, Eissenstat DM (2008) Root anatomy, morphology, and longevity among root orders in Vaccinium corymbosum (ericaceae). Am J Bot 95(12):1506-1514
Valverde-Barrantes OJ, Raich JW, Russell AE (2007) Fine-root mass, growth and nitrogen content for six tropical tree species. Plant Soil 290:357-370

Vogt KA, Vogt DJ, Palmiotto PA, Boon P, Ohara J, Asbjornsen H (1996) Review of root dynamics in forest ecosystems grouped by climate, climatic forest type and species. Plant Soil 187:159-219

Volder A, Gifford RM, Evans JR (2007) Effects of elevated atmospheric $\mathrm{CO}_{2}$, cutting frequency, and differential day/ night atmospheric warming on root growth and turnover of Phalaris swards. Glob Chang Biol 13:1040-1052

Wells CE, Glenn DM, Eissenstat DM (2002) Changes in the risk of fine-root mortality with age: a case study in peach, Prunus Persica (rosaceae). Am J Bot 81(1):79-87

Wen X, Wang H, Wang J, Yu G, Shun X (2010) Ecosystem carbon exchanges of a subtropical evergreen coniferous plantation subjected to seasonal drought, 2003-2007. Biogeosciences 7: 357-369

West JB, Espeleta JF, Donovan LA (2004) Fine root production and turnover across a complex edaphic gradient of a Pinus palustris-Aristida stricta savanna ecosystem. For Ecol Manag 189:397-406

Wilcox CS, Ferguson JW, Fernandez GCJ, Nowak RS (2004) Fine root growth dynamics of four Mojave desert shrubs as related to soil moisture and microsite. J Arid Environ 56:129-148

Xia M, Guo D, Pregitzer KS (2010) Ephemeral root modules in Fraxinus mandshurica. New Phytol 188:1065-1074

Xu W, Liu J, Liu X, Li K, Zhang D, Yan J (2013) Fine root production, turnover, and decomposition in a fast-growth Eucalyptus urophylla plantation in southern China. J Soils Sediments 13:1150-1160 